\title{
Avanços e desafios da enfermagem na produção científica sobre Psoríase
}

\author{
Advances and challenges of nursing in the scientific production on Psoriasis
}

Avances y desafíos de la enfermería en la producción científica acerca de Psoriasis

\section{Cristina Silva Arruda', Eliza Nogueira', Milena Silva de Oliveira', Eliane Ramos Pereira', Rose Mary Costa Rosa Andrade Silva' \\ 'Universidade Federal Fluminense. Escola de Enfermagem Aurora de Afonso Costa. Niterói, RJ}

Submissão: $30 / 07 / 2009$

Aprovação: 12/09/2010

\section{RESUMO}

A Psoríase, doença crônica de causa ainda incerta, atinge I a 3\% da população mundial e gera grande impacto psicológico e modificações na Qualidade de vida, constituindo desafiadora realidade. Objetivou-se analisar a produção científica de enfermagem sobre Psoríase, entre 1997/2008, examinando-se abordagens e contribuições para o cuidado. Estudo bibliográfico em base virtual de dados Medline, utilizando-se os termos "Psoríase" e "Enfermagem". Dos 21 artigos selecionados, 19\% enfocam a fisiopatologia e diagnóstico diferencial, $48 \%$ tratamento, $28 \%$ aspectos psicológicos e $42 \%$ cuidados de enfermagem. O resgate desse saber científico reforça o desafio de maximização da produção acerca da temática, trazendo contribuições para avanços mais expressivos Que visem uma intervenção mais holística e de maior Qualidade junto a essa clientela.

Descritores: Psoríase; Enfermagem; Assistência de enfermagem.

\section{ABSTRACT}

The Psoriasis, chronic disease with uncertain cause, affects 1 to $3 \%$ of world population, produces great psychological impact and changes in Quality of life, a challenging reality. The objective is to analyze the scientific production of nursing on Psoriasis in 1997/ 2008, examining the approaches and contributions to care. Bibliographic study based on virtual database Medline using the terms "Psoriasis" and "Nursing". Of the 21 articles selected, 19\% focus on the pathophysiology and differential diagnosis, 48\% treatment, $28 \%$ psychological aspects and $42 \%$ in nursing care. The rescue of the scientific knowledge increases the challenge of maximizing the scientific production about this subject, bringing significant contributions to advances to a more holistic intervention and higher Quality with this clientele.

Key words: Psoriasis; Nursing; Nursing care.

\section{RESUMEN}

La Psoriasis, enfermedad crónica de causa incierta aflige 1 a 3\% de la población mundial, produce varios efectos psicológicos y los cambios en la calidad de vida, una realidad desafiante. El objetivo es analizar la producción científica de la enfermería en la Psoriasis en 1997/2008, los enfoques y las contribuciones a la atención. Estudio bibliográfico por base de datos virtual Medline con los termos "Psoriasis" e "Enfermería”. De los 21 artículos seleccionados, 19\% se centran en la fisiopatología y el diagnóstico diferencial, 48\% tratamiento, $28 \%$ psicológica y $42 \%$ atención de enfermería. El rescate del conocimiento científico aumenta el desafío de maximizar esta producción científica, ofreciendo importantes contribuciones a los avances del conocimiento para una intervención más global y de mayor calidad con esta clientela.

Descriptores: Psoriasis; Enfermería; Atención de enfermería. 


\section{INTRODUÇÃO}

$\mathrm{Na}$ atual era de avanços científicos extraordinariamente progressivos, há uma necessidade de ampliação da informação aproximando e consolidando saberes, rompendo avanços e gerando novos conhecimentos. No Que diz respeito à enfermagem como profissão, a produção do conhecimento científico tem mostrado um esforço em conjunto procurando desenvolver uma enfermagem na Qual o cuidado de eualidade deva assumir a primazia do nosso pensar e do nosso fazer. Essa essência se percebe na crescente busca da produção do saber que emerge de um legado e impulsiona para novos patamares da pesquisa, fazendo a diferença em nossa geração.

A evidência de expressiva produção e divulgação do saber da enfermagem, firmada na intercessão de variadas instâncias interdisciplinaridade, e na pluralidade do conhecimento científico, tem alavancado grandes conQuistas na profissão, sobrepujando muitos paradigmas e desafios.

Nesse sentido, a produção de novos conhecimentos na enfermagem é primordial, pois "sem esquecer o passado, viveremos e construiremos o presente na perspectiva da superação dos desafios Que se apresentarão em nosso futuro"(1). Da mesma forma, o reconhecimento de uma profissão em âmbito nacional e internacional e assim como sua visibilidade no cenário científico se faz na medida em Que esta produza ciência e, mais do Que isto, divulgue o Que produz, sendo isto evidenciado pelo volume da produção publicada em periódicos científicos da área específica ou das áreas afins ${ }^{(2)}$.

Preliminarmente, convém destacar Que a Psoríase é uma doença dermatológica, inflamatória da pele, não contagiosa e crônica, Que atinge de $\mathrm{I}$ a $3 \%$ da população mundial e se manifesta em pessoas de todas as idades e de ambos os sexos, atingindo igualmente homens e mulheres, sendo mais frequente na raça branca. A doença pode se manifestar logo após o nascimento ou tardiamente no idoso, entretanto é mais comum ter seu início entre a $2^{\mathrm{a}}$ e a $4^{\mathrm{a}}$ décadas de vida ${ }^{(3)}$.

Apesar de possuir causa ainda desconhecida, fenômenos emocionais são frequentemente relacionados com o seu surgimento ou agravamento. Entre eles estão o estresse e o uso de certos medicamentos, as mudanças climáticas e algumas doenças como diabetes; Que atuam como fatores desencadeantes de uma predisposição genética para a doença. Além disso, cerca de 30\% das pessoas Que possuem Psoríase apresentam histórico de familiares também acometidos por ela ${ }^{(4-5)}$.

A doença caracteriza-se principalmente pelo aparecimento de lesões róseas ou avermelhadas, recobertas de escamas secas e esbranQuiçadas Que se alternam em períodos agudos com fases de piora e de melhora. As principais regiões afetadas são os joelhos, cotovelos, couro cabeludo, palmas das mãos e sola dos pés e, em razão de suas características, pode ser confundida com outras doenças, tais como micose, alergia e câncer de pele. Em alguns casos, pode apresentar-se sistemicamente e assim se espalhar por todo corpo ${ }^{(4)}$.

Por ser de curso crônico, não possuindo cura, a meta de seu tratamento constitui em retardar a velocidade de reprodução das células epidérmicas, Que se encontra mais rápida Que o normal nestes casos, buscando solucionar as lesões psoríticas e controlar o ciclo natural da doença. Assim, o tratamento a ser empregado dependerá do grau de suas manifestações e do comprometimento Que estas ocasionam ${ }^{(6-7)}$.

A enfermagem sendo componente essencial da equipe de saúde
Que presta assistência a esse paciente deve focalizar seu cuidado em como ele lhe dá com sua enfermidade e Qual o seu real impacto, já Que esta doença está diretamente ligada à Questão da aparência das lesões e, portanto, da auto-imagem; do risco de infecções já Que a pele encontra-se com sua integridade prejudicada e com o déficit de conhecimento sobre a doença e seu tratamento, podendo levar a Quadros de depressão e dificuldades de interação social.

Além disso, é da competência do enfermeiro Qualificar sua equipe de enfermagem para uma assistência integral eficaz ao cliente acometido pela doença, inclusive no aspecto psicoemocional,e na maneira de lidar, evitando possíveis constrangimento frente ao paciente.

Assim, o objeto deste estudo é a produção científica sobre Psoríase elaborada pela enfermagem, tendo como objetivos analisar a produção científica de enfermagem sobre psoríase, em uma base de dados virtual, examinando-se abordagens e contribuições para o cuidado de enfermagem.

\section{MÉTODOS}

Diante do proposto, o estudo do tipo bibliográfico tendo sido realizado uma revisão de literatura através de bases virtuais de dados. E, por compreender uma grande amplitude de publicações e temáticas nas diversas áreas da saúde, a base de dados utilizada para o desenvolvimento deste método foi Medline. Convém informar Que não foi encontrada QualQuer produção nas bases virtuais Scientific Eletronic Library Online (SciELO), Literatura LatinoAmericana e do Caribe em Ciências da Saúde (LILACS) e demais no âmbito da Biblioteca Virtual em Saúde, utilizando-se, em português e inglês, o termo Psoríase associado à enfermagem. Isso veio a reforçar a importância desse estudo.

Para se obter uma relação entre as publicações específicas da enfermagem com o tema principal, foram utilizados como descritores "Psoríase/Psoriasis" e "Enfermagem/Nursing" em português e inglês. Foram encontrados 53 artigos publicados no período entre os anos de 1997 a 2008, entretanto foram incluídos neste estudo apenas 2 I destes. Os critérios de exclusão considerados foram: publicação em outra língua além de português e inglês e a não disponibilidade do texto online.

A análise foi realizada através do agrupamento dos artigos por Quatro áreas temáticas equivalentes, construídas pelos autores e observadas por sua frequência de aparição.

A publicação científica de enfermagem acerca de Psoríase foi analisada e os artigos foram agrupados Quanto ao enfoque apresentado, tendo sido construídas categorias Quanto à fisiopatologia e investigação de diagnóstico diferencial, tratamentos desenvolvidos atualmente, os reflexos psicológicos gerados no paciente portador de psoríase e os cuidados gerais de enfermagem. Essas áreas temáticas foram estudadas separadamente e analisadas Quanto à sua devida contribuição para o cuidado de enfermagem a pacientes portadores de Psoríase.

\section{RESULTADOS E DISCUSSÃO}

Como resultado obteve-se a avaliação dos $2 \mathrm{I}$ artigos dentre os Quais $19 \%$ referiu-se à fisiopatologia e o diagnóstico diferencial, $48 \%$ sobre o tratamento, $28 \%$ sobre os aspectos psicológicos, e $42 \%$ sobre os cuidados de enfermagem. 
Acreditamos Que essas categorias são de fundamental importância para o atendimento de enfermagem a estes pacientes, pois possibilitam a discussão de novos achados diagnósticos e de novas terapias, propiciando avanços a partir dos conhecimentos já adouiridos.

Assim, se segue à discussão específica de cada categoria considerando os artigos incluídos no estudo. Muitos trazem mais de uma perspectiva e são referenciados em mais de uma categoria.

\section{Enfermagem e o enfoque na fisiopatologia e diagnóstico diferencial da Psoríase}

Dos artigos analisados 19\% $(n=4)$ aborda sobre a fisiopatologia da Psoríase, conforme é apresentado na Tabela 1.

Por apresentar diversas formas de apresentação, a Psoríase é classificada de acordo com a área atingida e sua gravidade em: severa, moderada e leve. A Academia Americana de Dermatologia classifica-a como severa Quando esta afeta $10 \%$ da extensão corporal, como moderada Quando de 3 a 10\% do corpo afetado e leve Quando até $2 \%$ apresenta lesões.

De forma geral podemos considerar todas as suas formas como severas, pois todas elas geram modificações na Qualidade de vida dos pacientes, afetando-o psicologicamente, mesmo Que seus sintomas afetem uma pequena área do corpo, como as palmas das mãos Que eQuivalem a cerca de $1 \%$ da superfície do corpo $^{(8)}$.

Normalmente, as células da pele se reproduzem e proliferam em aproximadamente 28 dias. Durante esse processo as células migram para a camada basal da epiderme. Na Psoríase o ciclo das células é acelerado, podendo ser reduzido a Quatro dias. Essa diminuição no tempo prejudica a maturação apropriada das células e produzem falhas em sua Queratinização. ConseQuentemente há um acúmulo de Queratina na camada córnea, resultando nas características apresentadas pela Psoríase ${ }^{(9)}$.

Não se sabe a causa exata da Psoríase, entretanto, fatores ambientais e genéticos são considerados fatores-causa. Um estudo anterior constatou em uma grande amostra populacional, Que sua incidência é alta em pacientes Que possuem parentes próximos, de primeiro e segundo graus, Que também a possuem ${ }^{(9)}$. Em um outro estudo, desenvolvido entre irmãos gêmeos fraternos e idênticos, a incidência de psoríase também se mostrou elevada ${ }^{(12)}$.

Evidências crescentes sugerem a poligenia como componente para Psoríase. Genes múltiplos interagem com outros e com o ambiente ocasionando formas variadas de Psoríase ${ }^{(12)}$. Esses dados reforçam a suposição de Que a predisposição genética interfere significantemente para o desenvolvimento da Psoríase, entretanto novos estudos precisam ser desenvolvidos.

Fatores ambientais são igualmente complexos. O agravamento por fatores ambientais inclui: trauma, infecção, hormônios, luz do sol, medicamentos / drogas, álcool, fumo e estresse ${ }^{(13)}$.

O diagnóstico diferencial para Psoríase é feito através da análise clínica e comparação das lesões, mas alguns exames complementares também podem ajudar na exclusão de diagnósticos semelhantes.

Dos artigos encontrados $14 \%(n=3)$ aborda o tema de diagnósticos diferenciais, conforme apresentados na Tabela 2.

Pacientes propensos a artrite tem seu diagnóstico definido pela clínica sugestiva de inflamação (dor, limitação de movimento), mas não possuem diagnóstico específico de artrite reumática. Para a perspectiva clínica, o desenvolvimento da terapia baseia-se em sugestões dos aspectos clínicos, abrindo uma "janela de oportunidades" de hipóteses para intervenção terapêutica ${ }^{(10)}$.

Bielan ${ }^{(14)}$ descreve lesões de Psoríase nas mãos e pés realizando o diagnóstico diferencial utilizando um caso clínico, analisando o aspecto das lesões, levantando e comparando as hipóteses entre Tinea pedis; Psoríase com placas escurecidas de Tinea; Psoríase isoladamente e Psoríase associada ao Sarcoma de Kaposi ${ }^{(14)}$.

Segundo o mesmo, a Tinea Pedis pode sempre ser considerada em caso de descamação e para sua confirmação pode-se realizar o exame de $\mathrm{KOH}$ (hidróxido de potássio), onde as raspagens da pele são dissolvidas e depois examinadas ao microscópio, possibilitando resultado imediato. A confirmação do diagnóstico de Psoríase neste caso se deu através do histórico do paciente e

Tabela 1. Assuntos abordados nos artigos sobre fisiopatologia da Psoríase.

\begin{tabular}{|c|c|c|c|}
\hline Autor & Objetivo & Metodologia & Abordagem da fisiopatologia \\
\hline Daus $^{(8)}, 2008$ & $\begin{array}{l}\text { Focar a psoríase envolvendo mãos e pés em seus } \\
\text { aspectos físicos e Qualidade de vida e tratamento }\end{array}$ & Revisão de literatura & $\begin{array}{l}\text { Aborda principalmente a fisiopatologia da psoríase } \\
\text { me mãos e pés. }\end{array}$ \\
\hline $\operatorname{Ryan}^{(9)}, 2008$ & $\begin{array}{l}\text { Analisar as características, etiologia, tratamento } \\
\text { e efeitos psicossociais da psoríase. }\end{array}$ & Revisão de literatura & $\begin{array}{l}\text { Aborda a fisiopatologia de forma clara e a etiologia } \\
\text { da doença relacionando-as. }\end{array}$ \\
\hline $\begin{array}{l}\text { Miedany } \\
\text { et } \mathrm{al}^{(10)}, 2006\end{array}$ & $\begin{array}{l}\text { Desenvolver um protocolo discriminando em } \\
\text { categorias os diferentes inícios de artrite. }\end{array}$ & $\begin{array}{l}\text { Pesquisa clínica } \\
\text { experimental }\end{array}$ & $\begin{array}{l}\text { Aborda a fisiopatologia de forma informativa, dando } \\
\text { ênfase a psoríase artrítica. }\end{array}$ \\
\hline Gottlieb $^{(1 I)}, 2003$ & $\begin{array}{l}\text { Definir artrite psoriática, seus efeitos na } \\
\text { Qualidade de vida do paciente e o papel do } \\
\text { enfermeiro. }\end{array}$ & Revisão de literatura & $\begin{array}{l}\text { Aborda a fisiopatologia com ênfase na psoríase } \\
\text { artrítica. }\end{array}$ \\
\hline
\end{tabular}

Tabela 2. Estudos Que abordam diagnósticos diferenciais para Psoríase.

\begin{tabular}{|c|c|c|c|}
\hline Autor e ano & Objetivo & Metodologia & Diagnósticos diferenciais \\
\hline Miedany $^{(10)}, 2006$ & $\begin{array}{l}\text { Desenvolver um protocolo discriminando em } \\
\text { categorias os diferentes inícios de artrite, } \\
\text { encurtando o tempo de diagnóstico e manejo da } \\
\text { doença. }\end{array}$ & $\begin{array}{l}\text { Pesquisa clínica } \\
\text { experimental }\end{array}$ & $\begin{array}{l}\text { Diagnóstico diferencial utilizado para artrite } \\
\text { psoriática. }\end{array}$ \\
\hline $\begin{array}{l}\text { Bielan }^{(14)} \\
2005\end{array}$ & $\begin{array}{l}\text { Descrever as lesões em mãos e pés, para } \\
\text { diferenciar diagnóstico. }\end{array}$ & $\begin{array}{l}\text { Estudo de caso/ } \\
\text { descritiva }\end{array}$ & $\begin{array}{l}\text { Descreve as lesões de mãos e pés, diferenciando o } \\
\text { diagnóstico e observando diagnósticos associados. }\end{array}$ \\
\hline $\begin{array}{l}\text { Bielan }^{(15)}, \\
2002\end{array}$ & $\begin{array}{l}\text { Descrever as lesões em mãos e pés, para } \\
\text { diferenciar diagnóstico. }\end{array}$ & $\begin{array}{l}\text { Estudo de caso/ } \\
\text { descritiva }\end{array}$ & $\begin{array}{l}\text { Descrevendo as lesões da região das nádegas, } \\
\text { diferenciando o diagnóstico e observando } \\
\text { diagnósticos associados. }\end{array}$ \\
\hline
\end{tabular}


pela apresentação de placas similares nos cotovelos, aberturas entre a pele e as unhas, além disso, as placas de tinea são superficiais, não atingem camadas da derme, portanto pacientes com Psoríase em mãos e pés dificilmente desenvolveriam Tinea Pedis. Quanto à suspeita de Sarcoma de Kaposi, foi realizada biópsia do local da lesão, confirmando este diagnóstico juntamente com as lesões psoríticas. Ele ainda justifica-se pela não localização anatômica preferencial do sarcoma, podendo surgir em Qualquer local da pele e até nas membranas mucosas orais, genitais ou oculares ${ }^{(12)}$.

Bielan $^{(14)}$ descreve lesões nas nádegas e realiza a discussão entre o diagnóstico diferencial, analisando o aspecto das mesmas, levantando as hipóteses de Psoríase, Líuuen Simples Crônico, Eczema Numular e Tinea Corporis. Neste caso, a clínica apresentada era similar ao caso de Psoríase, entretanto era pouco provável Que se confirmasse porque as lesões psoríticas inserem-se em um sítio por muitos anos e este não apresentava outras lesões em locais clássicos, como cotovelo, joelhos. No Líeuen Simples Crônico ocorre constante prurido causado pela lesão, levando ao espessamento local progressivo da pele, o Que pode levar muitos pacientes a piorar as lesões; sendo esta a resposta para o caso clínico apresentado neste caso. No Eczema Numular, as lesões ocorrem mais comumente nas extremidades do corpo e também apresentam prurido intenso, por isso a suspeita. $\mathrm{E}$ Quanto a Tinea Corporis, causada por fungos dermatófitos, também ocorre prurido intenso e placas, mas estas são eritematosas e aumentadas nas bordas, com o centro mais claro ${ }^{(15)}$.

\section{Enfermagem e o tratamento da Psoríase}

O tratamento da Psoríase pode ser dividido em tópico, sistêmico e fototerápico. De forma geral, o tratamento tópico é utilizado em casos leves a moderados, o fototerápico para casos onde a doença

Tabela 3. Tratamento da Psoríase relatados nos artigos. apresenta-se de moderada a grave e o sistêmico apenas para as formas graves. Entretanto, nada impede Que se adotem dois desses tipos de tratamentos para o manejo de um único caso.

A escolha do tratamento deve ser avaliada a cada caso, considerando a ação Que irá desempenhar sobre a Qualidade de vida desse paciente e sobre a apresentação das lesões ${ }^{(25)}$.

Dos artigos analisados, 48\% $(n=10)$ deles (Tabela 3$)$ retrata alguma forma de tratamento para a Psoríase, Que será discutida adiante.

Anteriormente a eleição da medicação, deve-se analisar os fatores precipitantes e/ou agravantes da doença para aquele indivíduo observando seu estilo de vida, pois como visto, em muitas ocasiões é neste fator Que se nota o início da mesma ${ }^{(3)}$. Além disso, o paciente e a família devem ser orientados Quanto esta terapia, já Que muitas vezes pode ser esteticamente desagradável e trazer grandes modificações nos hábitos de vida ${ }^{(4-5)}$.

A terapia farmacológica varia em três formas: a tópica, Que incluí loções, pomadas, pastas, cremes e xampus que são formados por agentes Que diminuem a hiperatividade da epiderme não interferindo em outros tecidos; a intralesional, apresentada na forma de injeções Que podem ser aplicadas diretamente nas placas psoríticas visíveis ou isoladas, resistentes a outras terapias, evitandose Que as partes não afetadas sejam atingidas pela medicação; e a sistêmica utilizada para formas graves da doença ${ }^{(4)}$.

\section{Alguns destaques sobre o Tratamento Tópico}

Esta forma de tratamento é a mais utilizada nos casos de Psoríase, pois mesmo em casos mais graves sua adoção certamente será exigida em alguma fase. $\mathrm{O}$ tratamento tópico pode exigir muito do paciente, gerando certos incômodos e modificações nos hábitos de vida. Elevado

\begin{tabular}{|c|c|}
\hline Autor / Ano & Objetivo \\
\hline $\operatorname{Ryan}^{(9)}, 2008$ & $\begin{array}{l}\text { Analisar as características, etiologia, tratamento } \\
\text { e efeitos psicossociais da psoríase. }\end{array}$ \\
\hline Lawton $^{(16)}, 2007$ & $\begin{array}{l}\text { Explorar a função da pele como barreira, os } \\
\text { fatores Que a influenciam e o uso de emolientes. }\end{array}$ \\
\hline $\begin{array}{l}\text { Miedany, Palmer e } \\
\text { Gaafary }^{(10)}, 2006\end{array}$ & $\begin{array}{l}\text { Desenvolver um protocolo discriminando em } \\
\text { categorias os diferentes inícios de artrite, } \\
\text { encurtando o tempo de diagnóstico e manejo da } \\
\text { doença. }\end{array}$ \\
\hline Melton $^{(17)}, 2005$ & $\begin{array}{l}\text { Relatar aspectos físicos e psicológicos de um } \\
\text { prisioneiro de guerra com psoríase e o } \\
\text { tratamento utilizado. }\end{array}$ \\
\hline Riddoch $^{(5)}, 2005$ & $\begin{array}{l}\text { Descrever a importância do manejo de uma } \\
\text { clínica dermatológica pela enfermeira. }\end{array}$ \\
\hline Browman $^{(18)}, 2004$ & Descrever diversas formas de tratamento. \\
\hline Young $^{(19)}, 2003$ & $\begin{array}{l}\text { Familiarizar os enfermeiros com o papel do } \\
\text { sistema imune na psoríase e como as várias } \\
\text { etapas dessa resposta podem servir como alvos } \\
\text { terapêuticos. }\end{array}$ \\
\hline $\begin{array}{l}\text { Leone, Rolston e } \\
\text { Spauliding }^{(20)}, 2003\end{array}$ & $\begin{array}{l}\text { Analisar a eficácia e segurança, além de dados } \\
\text { sobre QV, do Alefacept e informações sobre sua } \\
\text { administração. }\end{array}$ \\
\hline Mikula $^{(21)}, 2003$ & $\begin{array}{l}\text { Descrever uma nova terapia holística no } \\
\text { tratamento da psoríase, demonstrando sua ação } \\
\text { por um estudo de caso. }\end{array}$ \\
\hline Gottlieb $^{(11)}, 2003$ & $\begin{array}{l}\text { Definir artrite psorítica, seus efeitos na QV, } \\
\text { discutir asabordagens atuais sobre o tratamento } \\
\text { e o papel do enfermeiro. }\end{array}$ \\
\hline
\end{tabular}

\begin{tabular}{|c|c|}
\hline Metodologia & Tratamento abordado \\
\hline Revisão de literatura & Agentes tópicos e sistêmicos \\
\hline Revisão de literatura & Emolientes \\
\hline $\begin{array}{l}\text { Peseuisa clínica } \\
\text { experimental }\end{array}$ & $\begin{array}{l}\text { Corticóides, anti-inflamatório não-esteróide e } \\
\text { DMARD. }\end{array}$ \\
\hline Estudo de caso & $\begin{array}{l}\text { Banhos de emersão, desbridamento das lesões, } \\
\text { uso de Morfina para dor e aplicação de hidratante. }\end{array}$ \\
\hline Descritivo & $\begin{array}{l}\text { Emolientes, esteróides, al catrão e fototerapia e } \\
\text { Quimioterapia. }\end{array}$ \\
\hline Estudo de caso & $\begin{array}{l}\text { Fototerapia, retinóides, imunossupressores, carvão } \\
\text { de alcatrão, análogos de vit D e emolientes. }\end{array}$ \\
\hline Revisão de literatura & Terapia molecular e uso de Efalizumab \\
\hline
\end{tabular}

Revisão de literatura Alecefacept

Revisão de literatura e Balneo-fototerapia

estudo de caso

Revisão de literatura

Etanercept, Infliximab, Metrotrexate, Sulfasalazine e Cyclosporine. discutir asabordagens atuais sobre o tratamento 
nível de frustração e insatisfação foi encontrado em pacientes Que utilizam esse método terapêutico, o Que exige do profissional de saúde grande apoio e observação Quanto à adesão ao tratamento ${ }^{(9)}$.

Os emolientes são utilizados em grande escala e possuem a função de ajudar na barreira lipídica da epiderme, prejudicada com a doença. São usados para lavar, hidratar e como manutenção da terapia, proporcionando uma melhora da textura da pele, redução da sua descamação, ofertando maior conforto e preparando a epiderme para terapias mais ativas, pois diminuem a perda de água para o meio extra dérmico. Entre outros efeitos menos explicados dos emolientes, estão a ação anti-inflamatória, antimitótica e anti-pruriginosa ${ }^{(16)}$.

Os análogos de vitamina D são anti-proliferativos e promovem a diferenciação da Queratina, sendo vantajosos agentes no tratamento de casos leves e moderados de Psoríase. Em geral, são bem tolerados pelos pacientes, mas podem causar irritação leve. Na presença de um algum tipo de doença severa seu uso deve ser desconsiderado, pois em altas doses há um grande risco de hipercalemia e hipercalciúria. O Calcitriol e o Tacalcitol são menos irritantes do Que o Calcipotriol, e podem ser utilizados na face e nas articulações ${ }^{(16)}$.

Também são disponíveis fármacos Que associam a vitamina $\mathrm{D}$ com cortiosteróides, e podem ser úteis no tratamento de casos resistentes, entretanto, devem ser usados com precaução devido à probabilidade de recaída da doença ou originar agravamento para psoríase pustular. Apesar de eficaz, o uso do Alcatrão no tratamento da psoríase está sendo desencorajado devido ao seu odor e coloração residual. Contudo, ele continua disponível como cremes, pomadas, emulsões e xampus ${ }^{(9)}$.

Os corticosteróides tópicos também são utilizados com suas devidas precauções, já que seu uso inadequado pode precipitar casos rebotes de psoríase, desestabilizando a doença e induzindo à forma pustulosa. Por isso, seu uso é limitado por áreas como face, couro cabeludo e articulações, e restrita a formulações mais suaves. Sua exceção está nos casos onde a lesão psorítica encontra-se na forma palmar-plantar, onde potentes corticosteróides tópicos podem ser usados ${ }^{(9)}$.

\section{Acerca do Tratamento Fototerápico}

$\mathrm{Na}$ falha da reposta do tratamento tópico, busca-se a adoção do tratamento secundário Que pode ser a fototerapia ou fotoquimioterapia ${ }^{(5)}$. A fototerapia é a irradiação de raios UVB enQuanto a fotoquimioterapia utiliza a associação da irradiação UVA em conjunto a uma droga fotoativa ${ }^{(9)}$. Apesar de serem de fácil manejo, oferecem a desvantagem de ser realizada de duas a três vezes na semana, obrigando o paciente a comparecer ao atendimento hospitalar. Além disso, em longo prazo essa prática oferece o risco de malignidade cutânea ${ }^{(7)}$.

A balneo-fototerapia, na Qual o paciente era exposto a luz solar logo após tomar um banho em água rica em magnésio durante Quatro a seis semanas, foi sofrendo modificações. Atualmente, uma máQuina específica é responsável pela saturação de sais na água Que varia de $5 \%$ a $15 \%$, de acordo com a apresentação da doença e depois do contato com essa solução a pele é exposta a radiação ultravioleta B. Os efeitos adversos são: Queimaduras, hiperpigmentação, prurido, vesículas, Queimadura da córnea se os olhos estiverem desprotegidos ou fotosensibilidade ${ }^{(21)}$.

Enfoques do Tratamento Sistêmico

Anteriormente, a adoção desta forma de terapia muitos pacientes
Que falhavam em seus esquemas tópicos eram admitidos repetitivamente nos hospitais, com formas mais extensas e graves da doença, como a psoríase postulosa generalizada, eritrodermia e artropatia psorítica. Apesar da melhora atingida nesses casos, o tratamento sistêmico adotado por longo prazo pode originar diversos efeitos secundários tóxicos sendo, portanto, apenas utilizado através de uma conduta de supervisão que garanta suporte ao paciente e reposta rápida a QualQuer intercorrência.

Melton $^{(17)}$ relata Que em caso grave de Psoríase, onde não havia nenhum tipo de recurso adeQuado, foi tratado com terapia anal-gésica através de morfina, o uso de banhos de emersão, terapia de conservação de calor através de cobertores, a aplicação de agentes hidratantes e o desbridamento das placas psoríticas, e atingiram um resultado bastante significativo mostrando que em muitos casos mesmo graves, a adoção de terapias mais simples pode ser sufi-ciente.

A eleição da droga ou da combinação de drogas a ser empregada dependerá da ocorrência de doenças pré-existentes (co-morbidades), dos tratamentos anteriores e do estilo de vida ${ }^{(9)}$. Geralmente incluem-se no tratamento sistêmico (via oral) os retinóides ou imunossupressores, tendo como possíveis efeitos colaterais, a supressão da medula óssea e insuficiência renal ${ }^{(18)}$.

Nos últimos anos, um novo grupo de agentes sistêmicos tem sido criado para o uso na psoríase, devido ao conhecimento de Que a doença tem sua origem no funcionamento inadequado do sistema imunológico, principalmente no Que diz respeito à ativação de linfócitos $\mathrm{T}^{(19)}$. Essas drogas são conhecidas como biológicas, pois são formulados através de derivados de fontes de estruturas humanas, animais e/ou de plantas, mas seu uso deve ser controlado, pois geram alto custo para os sistemas de saúde e possuem alto potencial de efeitos colaterais graves ${ }^{(9)}$.

Três diferentes tipos de terapias biológicas vêm sendo estudados para doenças dermatológicas: os anticorpos monoclonais, as proteínas recombinantes humanas, e a fusão de proteínas. Os anticorpos monoclonais são produzidos através de engenharia recombinante buscando vincular-se com a célula-alvo em Questão. lá a criação de proteínas recombinantes humanas se dá através de cópias de proteínas humanas normais Que devem determinar alguma resposta fisiológica; entretanto, nenhuma ainda foi comprovadamente eficaz. A fusão de proteínas constitui no aglutinamento de duas proteínas com uma toxina Que resultará em morte celular, elas devem ser infundidas a um receptor humano específico Que permitirá Que sua ação seja direcionada a um determinado componente celular. Como exemplo, podemos destacar o Etanercept, utilizado no tratamento da artrite psorítica ${ }^{(19)}$.

Young ${ }^{(19)}$ apresenta ainda a ação do Efalizumab (Raptiva ${ }^{\mathrm{TM}}$ ), um modelador das células T Que controla sua ativação e migração para a epiderme, através de administração intravenosa e subcutânea. Em um estudo, pacientes Que o tomaram durante 12 semanas apresentaram melhoras em sua Qualidade de vida Quando comparados ao grupo placebo.

O Alefacept (Amevive ${ }^{\circledR}$, Biogen, Cambridge, MA), uma proteína recombinante por infusão Que diminui a circulação de células $T$ de memória, utilizada no tratamento da psoríase moderada e grave. Em um estudo feito com 229 pacientes Que receberam este medicamento via intravascular em bolus ou placebo durante 12 semanas, mostrou Que $24 \%$ das pessoas do grupo medicado com Alecept obteve o desaparecimento completo ou parcial de suas lesões, enQuanto apenas 
$5 \%$ do grupo placebo demonstrou alguma melhora. Este medicamento é geralmente bem tolerado e as reações adversas encontradas foi injúria, cefaléia, faringite, rinite, e prurido ${ }^{(20)}$.

No tratamento para artropatia psorítica (PsA) o único tratamento aprovado é o Etanercept, um inibidor de TNF, os outros tratamentos indicados para esses casos são os mesmos utilizados para outras doenças imunológicas. Este deve ser administrado por via subcutânea, duas vezes por semana. Pacientes em uso de Etanercept podem receber vacinas concomitantemente, mas devem evitar vacinas com antígenos vivos. Outros medicamentos como o Infliximab, Methrotrexat, o Sulfasalazine e Cyclosporine já foram utilizados para o tratamento de PsA, mas ainda estão em estudos ${ }^{(11)}$.

\section{Enfermagem enfocando os aspectos psicológicos da doença}

Dos artigos encontrados $28 \%(n=6)$ abordam os aspectos psicológicos do paciente e seu impacto na Qualidade de vida (Tabela 4).

A Psoríase é uma doença com profundas conseQuências psicossociais, pois apresenta o fato de ser visível superficialmente. Há significante morbidez entre pessoas com esta doença, com grande porcentagem de privação de atividades normais e sociais.

Indivíduos com psoríase apresentam estresse e dificuldades em seu local de trabalho, relacionamento interpessoal, emprego e no uso de transporte e áreas de lazer públicas. Essas dificuldades diminuem a interação social, facilitando o isolamento e a depressão. A profunda morbidez, disfunção física e psicossocial causada por esta doença, podem ser comparadas a experiências similares de pacientes com câncer, artrite, hipertensão, doenças do coração, diabetes e depressão $0^{(9,22)}$.

O impacto da doença na vida do paciente pode ser avaliada minuciosamente no aspecto biopsicossocial, estruturada no Healthrelated Quality of Life (HrQL) Que possui Quatro domínios: ocupacional, emocional, estado psicológico e interação social, e sensações físicas ${ }^{(22)}$.

Reconhecendo as experiências humanas múltiplas e complexas e suas individualidades consideramos os Quarto níveis: (a) o físico natural, dimensão material (o físico incorporado a existência, sua interpretação de mundo); (b) o social e cultural, dimensões públicas (atividades desenvolvidas socialmente, com outras pessoas, entre contradições, precisando pertencer a algum grupo e lidar com a

Tabela 4. Aspectos psicológicos abordados nos artigos. possibilidade de isolamento, atitudes e valores sobre raça, cultura, classe social, regras sociais, gênero); (c) o particular, e dimensões psicológicas (a consciências das pessoas, seu nível humano de experiências, tensão entre integridade e desintegração); (d) e o espiritual, interpretações e a dimensão ideológica, sobre si mesmo (a existência humana e espiritual, senso de valores, ideologias, olhar sobre a vida, morte e existência) ${ }^{(23)}$.

Em recentes pesquisas pela National Psoriasis Foundation em 2002, 84\% de 27.000 indivíduos pesquisados diagnosticados com psoríase apresentaram um impacto de moderado a significativo no desenvolvimento de suas atividades; $75 \%$ apresentaram insônia ou não conseguiam dormir o suficiente; $69 \%$ sentiam Que a doença interferia em suas atividades sociais e $25 \%$ estavam insatisfeitos com o tratamento ${ }^{(25)}$.

Diante da variada e complexa repercussão da doença na vida do cliente, há necessidade de um empenho coletivo multiprofissional. Aliás, os processos de produção de saúde constituem um trabalho coletivo e cooperativo, entre sujeitos, Que se faz numa rede de relações Que exige interação e diálogo permanentes e importa cuidar dessa rede de relações, especialmente, no cuidado de enfermagem $^{(26)}$. Esse trabalho em conjunto reforçará, com certeza, os benefícios ao cliente com Psoríase pois, o cuidado a essa clientela deve enfaticamente envolver o empenho e intervenção multidisciplinar com vistas à uma abordagem holística de Qualidade.

\section{Cuidados de enfermagem}

Dos 21 artigos encontrados, 43\% $(n=9)$ enfoca os cuidados de enfermagem ao cliente com psoríase, sendo descritas na Tabela 6 , as principais abordagens de condutas enfatizadas nas publicações (Tabela 5).

Os cuidados de enfermagem com a Psoríase abordados nos artigos estão voltados principalmente: a) na orientação ao paciente, estimulando-o e orientando-o Quanto à melhoria da Qualidade de vida através de apoio, aconselhamento, educação e satisfação de suas necessidades médicas e emocionais, procurando envolver o paciente e seu cuidado nos cuidados diários, tendo como retorno o tratamento precoce e adequado, orientando- o sobre a importância de não "coçar" as lesões; b) Qualificação dos profissionais de enfermagem para o tratamento eficaz da Psoríase; c) nos cuidados

\begin{tabular}{|c|c|c|c|}
\hline Autor/ ano & Objetivos & Metodologia & Abordagem dos aspectos psicológicos \\
\hline Daus $^{(8)}, 2008$ & $\begin{array}{l}\text { Focar a psoríase em seus aspectos físicos, } \\
\text { Qualidade de vida e tratamento }\end{array}$ & Revisão de literatura & $\begin{array}{l}\text { Questionamentos sobre atividades de cotidiano } \\
\text { envolvendo mãos e pés psoríticos. }\end{array}$ \\
\hline $\operatorname{Ryan}^{(9)}, 2008$ & $\begin{array}{l}\text { Analisar as características, etiologia, tratamento } \\
\text { e efeitos psicossociais da psoríase. }\end{array}$ & Revisão de literatura & Aborda as conseQüências psicológicas da psoríase. \\
\hline Watson ${ }^{(23)}, 2007$ & $\begin{array}{l}\text { Analisar as experiências e dimensões da doença } \\
\text { de pele e seu impacto na vida do paciente }\end{array}$ & $\begin{array}{l}\text { Qualitativo, } \\
\text { fenomenológico, } \\
\text { exploratório }\end{array}$ & $\begin{array}{l}\text { Descreve experiências de homens e mulheres Que } \\
\text { sofrem de psoríase e o impacto em sua auto- } \\
\text { concepção. }\end{array}$ \\
\hline$J^{\text {Jankowiak }}{ }^{(24)}, 2004$ & $\begin{array}{l}\text { Determinar a necessidade da educação em } \\
\text { saúde um pacientes com psoriase }\end{array}$ & Quantitativa & $\begin{array}{l}\text { Analisa Quantitativamente o nível de conhecimento } \\
\text { dos pacientes com psoríase sobre sua doença e } \\
\text { verifica os locais onde essa educação em saúde } \\
\text { ocorre e sua importância psicológica. }\end{array}$ \\
\hline Weiss $^{(22)}, 2003$ & $\begin{array}{l}\text { Definir saúde relacionada à Qualidade de vida; } \\
\text { discutir psoríase e como a esta afeta e descrever } \\
\text { aplicações de enfermagem. }\end{array}$ & Revisão de literatura & Demonstra a utilização do HRQL \\
\hline Gottlieb $^{(11)}, 2003$ & $\begin{array}{l}\text { Definir artrite psorítica, seus efeitos na } \\
\text { Qualidade de vida e discutir as abordagens atuais } \\
\text { sobre o tratamento e o papel do enfermeiro. }\end{array}$ & Revisão de literatura & $\begin{array}{l}\text { Aborda a influência da artrite psorítica na } \\
\text { Qualidade de vida dos pacientes }\end{array}$ \\
\hline
\end{tabular}


Tabela 5. Cuidados de Enfermagem dos apresentados nos artigos.

\begin{tabular}{|c|c|c|c|}
\hline Autor/ ano & Objetivos & Metodologia & Abordagem dos cuidados de enfermagem \\
\hline Daus $^{(8)}, 2008$ & $\begin{array}{l}\text { Focar a psoríase envolvendo mãos e pés em } \\
\text { seus aspectos físicos e Qualidade de vida e } \\
\text { tratamento }\end{array}$ & Revisão de literatura & $\begin{array}{l}\text { Estimular e orientar o paciente Quanto à melhoria } \\
\text { da Qualidade de vida através de apoio, } \\
\text { aconselhamento, educação e satisfação de suas } \\
\text { necessidades médicas e emocionais. }\end{array}$ \\
\hline $\operatorname{Petros}^{(2 \pi)}, 2008$ & $\begin{array}{l}\text { Debater sobre a doença ou condição e a } \\
\text { fundamentação utilizada em cada etapa de } \\
\text { avaliação. }\end{array}$ & Estudo de Caso & $\begin{array}{l}\text { Ajudar na escolha do tratamento, apoio psicológico } \\
\text { e educação do paciente. }\end{array}$ \\
\hline Ryan $^{(9)}, 2008$ & $\begin{array}{l}\text { Analisar as características, etiologia, tratamento } \\
\text { e efeitos psicossociais da psoríase. }\end{array}$ & Revisão de literatura & $\begin{array}{l}\text { Qualificar os profissionais de enfermagem para o } \\
\text { tratamento eficaz da psoríase. }\end{array}$ \\
\hline Watson $^{(23)}, 2007$ & $\begin{array}{l}\text { Analisar as experiências e dimensões da doença } \\
\text { de pele e seu impacto na vida do paciente }\end{array}$ & $\begin{array}{l}\text { Qualitativo, } \\
\text { fenomenológico, } \\
\text { exploratório }\end{array}$ & $\begin{array}{l}\text { Procurar envolver o paciente e seu cuidador nos } \\
\text { cuidados diários, tendo como retorno o tratamento } \\
\text { precoce e adequado. }\end{array}$ \\
\hline Lawton $^{(16)}, 2007$ & $\begin{array}{l}\text { Explora a função da pele como barreira, os } \\
\text { fatores Que a influenciam e o uso de emolientes. }\end{array}$ & Revisão de literatura & $\begin{array}{l}\text { Manter as unhas do paciente cortadas, prevenindo } \\
\text { o surgimento de novas lesões, hidratar diariamente } \\
\text { a pele do paciente e manter o equilíbrio térmico, } \\
\text { hídrico e eletrolítico. }\end{array}$ \\
\hline $\begin{array}{l}\text { Winkelman e } \\
\text { Halifax }^{(28)}, 2007\end{array}$ & $\begin{array}{l}\text { Avaliar hábitos através de observação diária, } \\
\text { entrevista, reflexão crítica de documentos e } \\
\text { formulários, facilitando a prestação de cuidados } \\
\text { e trazendo benefícios sociais para estes } \\
\text { pacientes }\end{array}$ & $\begin{array}{l}\text { Pesquisa etnográfica } \\
\text { descritiva }\end{array}$ & $\begin{array}{l}\text { Gestão da enfermagem na administração de um } \\
\text { centro especializado e cuidados gerais com os } \\
\text { pacientes. }\end{array}$ \\
\hline Young $^{(19)}, 2006$ & $\begin{array}{l}\text { Sistema imune na psoríase e como suas etapas } \\
\text { podem interferir como alvos terapêuticos. }\end{array}$ & Revisão de literatura & $\begin{array}{l}\text { Avaliar o conhecimento do cliente (doença, } \\
\text { tratamento e auto-cuidado). }\end{array}$ \\
\hline Guldbakke $^{(29)}, 2006$ & $\begin{array}{l}\text { Discutir a apresentação clínica, incluindo } \\
\text { história, o tratamento, a educação do paciente, } \\
\text { e medidas.de enfermagem. }\end{array}$ & Estudo de Caso & $\begin{array}{l}\text { Realizar educação para o paciente sobre a doença e } \\
\text { o tratamento. }\end{array}$ \\
\hline $\begin{array}{l}\text { Grillo, Long e Long }{ }^{(30)} \text {, } \\
2007 .\end{array}$ & $\begin{array}{l}\text { Discutir os cuidados de saúde e educação para } \\
\text { os pacientes e suas famílias em relação ao } \\
\text { hábito formação .inversa. }\end{array}$ & Revisão de literatura & $\begin{array}{l}\text { Apresentar um esquema de manejo no tratamento } \\
\text { da doença. }\end{array}$ \\
\hline
\end{tabular}

práticos de enfermagem, como manter as unhas do paciente cortadas, prevenindo o surgimento de novas lesões, hidratar diariamente a pele do paciente, manter o equilíbrio térmico, hídrico e eletrolítico; e, d) avaliação do profissional através de observação diária, entrevista, reflexão crítica de documentos e formulários, facilitando a prestação de cuidados e trazendo benefícios sociais para estes pacientes, avaliar o conhecimento do cliente (doença, tratamento e auto-cuidado) e avaliar as influências da psoríase na vida do cliente.

A atitude dos médicos e enfermeiros em relação aos seus pacientes influencia no bem-estar destes e o aumento da autoestima está relacionado diretamente à recuperação psicológica ${ }^{(23)}$. Portanto, o cuidado de enfermagem vai além da competência técnica, mas sim um cuidado livre de preconceito, focalizado no ser humano, tendo a visão do ser na sua totalidade (física, emocional, social e espiritual). Enfermeiras desempenham um papel importante com os pacientes de Psoríase na melhoria de sua Qualidade de vida através de apoio, aconselhamento, educação e satisfação de suas necessidades médicas e emocionais ${ }^{(8)}$.

Na verdade, no Que se refere a problemas que de modo geral se assemelham nas Questões Que interferem na imagem corporal, o enfermeiro como profissional de saúde comprometido com saúde e bem-estar de sua clientela, deve buscar as novas coneuistas, novas descobertas, Que ao serem incorporadas ao cotidiano dos serviços de saúde, trazem benefícios às pessoas. Prevenir doenças, promover a cura, restituir saúde e bem-estar, entre outros, tornamse mais possíveis através das informações Que as pesquisas disponibilizam no mundo inteiro ${ }^{(31)}$.

Esse resgate da produção científica da enfermagem acerca dos conhecimentos voltados para o cuidar do cliente com psoríase nos reacende o compromisso com a necessidade de busca de novas perspectivas e vertentes do cuidar rumo a avanços acerca da temática, ampliando para uma visão social Que insere essa clientela.

Nesse sentido, convém destacar um dos objetivos da produção e disseminação de conhecimentos é o avançar na direção de modos de fazer ciência em enfermagem. Faz-se necessário examinarmos o caminho percorrido, evidenciando os limites e potencialidades de cada ação.

Frente à essa perspectiva, cabe reforçar Que o conhecimento deve estimular a cooperação, ser produzido em interação e interconexão com as necessidades sociais, visando, no Que se refere à saúde, promover um viver saudável para todos ${ }^{(32)}$.

\section{CONCLUSÃO}

A Psoríase continua sendo uma doença de causas indefinidas Que gera em seus portadores modificações estéticas e psicossociais, ocasionando alterações na Qualidade de vida dos pacientes e de seus familiares.

Com a análise desta revisão, constatou-se que a maioria dos artigos ainda se preocupa em retratar sobre as formas terapêuticas da Psoríase, seguindo pelos aspectos psicológicos, a fisiopatologia e os diagnósticos diferenciais, e por último discutir sobre cuidados específicos de enfermagem; mesmo que estes estudos tenham sido escritos por profissionais enfermeiros. 
A multiforme manifestação de intercorrências ligadas à doença traz a necessidade de um empenho multiprofissional, Que exige uma dinâmica de continuidade nas interfaces do cuidado.

Não se deve deixar de destacar a importância de cada assunto abordado e a evidente necessidade de novos estudos em todas essas áreas, já Que são essenciais para o desenvolvimento de uma melhor assistência a este paciente e por se tratarem ainda de estudos pouco conclusivos, Que ainda não marcam uma real definição para o aparecimento da doença, ou uma terapia Que garanta eficácia e poucas reações e ainda um manejo definido.

É preciso considerar Que a produção nacional de enfermagem sobre o assunto é expressivamente escassa, pois grande parte dos estudos é de origem americana. Isto nos faz refletir Que mesmo diante desta patologia em seu cotidiano profissional, a enfermagem brasileira ainda não está plenamente engajada no desenvolvimento de discussões sobre este cuidado.

Sendo a enfermagem profissão responsável pelo cuidado integral a este paciente, constitui-se grande desafio uma expressiva ampliação do conhecimento científico a ser aplicado à prática junto ao cliente acometido de psoríase através de novas pesquisas Que abordem um plano de cuidados mais claros e específicos, possibilitando a melhora da Qualidade do serviço a esses pacientes.

$O$ resgate de todo esse saber científico produzido pela enfermagem reforça a perspectiva de um evidente desafio a ser conQuistado Que é maximização da produção e divulgação do saber da enfermagem acerca desta temática, o Que, com certeza propiciará avanços mais expressivos ao conhecimento visando enfim os benefícios de uma intervenção mais holística e de maior Qualidade.

\section{REFERÊNCIAS}

1. Lopes MGD. A ABEn fortalecendo laços e construindo o futuro. Rev Bras Enferm 2008; 6I(1): 5-6

2. Cunha ICKO, Marques IR. Socializando a produção científica da Enfermagem do Piauí. Rev Bras Enferm 2007; 60(4): 369.

3. Psoríase Brasil. O Que é psoríase. Belo Horizonte; 2005. [citado em: 2009 Abril 7]. Disponível em: http://www.psoriase.org.br/ o_Que_e.html.

4. Araguaia M. Psoríase. Brasília; 2005. [citado em: 2009 Abril 7]. Disponível em: http://www.brasilescola.com/doencas/ psoriase.htm

5. Riddoch $\mathrm{C}$. The benefits of switching to nurse-led management of patients with psoriasis. Prof Nurse 2005; 20(5):38-40

6. Smeltzer SC, Bare BG. Brunner \& Suddarth: Tratado de Enfermagem Médico-Cirúrgica. 10 $0^{\text {a }}$ ed. Rio de Janeiro: Guanabara Koogan; 2005.

7. Silva KS, Silva EAT. Psoríase e sua relação com aspectos psicológicos, stress e eventos da vida. Estud Psicol 2007; 24(2): 257-66.

8. Daus L. Give them a hand: patients with hand and foot Psoriasis Require Special Attention. Dermatol Nurs 2008; 20(4): 29I-3.

9. Ryan S. Psoriasis: characteristics, psychosocial effects and treatment options. Br I Nurs 2008; 1 7(5):284-90.

10. Miedany YE, Palmer D, Gaafary ME. Diagnosis of early arthritis: outcomes of a nurse-led clinic. Br I Nurs 2006; 15(7): 394-9.

11. Gottlieb AB. Psoriatic arthritis: a guide for dermatology nurses. Dermatol Nurs 2003; 15(2): 107-10.

12. Barker JNWN. Genetic aspects of psoriasis. Clin Exp Dermatol 200I; 26(4): 32I-5.

13. Peter BP, Weissnian FG, Gill MA. Pathophysiology and treatment of psoriasis. Am I Health 2000; 57(7): 645-59.

14. Bielan B. What's your assessment? Psoriasis with Kapposi sarcoma. Dermatol Nurs 2005; I7(1): 30-I.

15. Bielan B. What's your assessment? Lichen simplex chronicus. Dermatol Nurs 2002; 14(4): 247-56.

16. Lawton S. Skin barrier function and the use of emollients in dermatological nursing. Br I Nurs. 2007; I 6(I 2): 7 I 2: 4-9.

17. Melton LP. Psoriasis in the war zone. Am I Nurs 2005; 105(3): 52-6.

18. Bowman I. Investigate all the options in skin care. Prof Nurse 2004; 19(I I): 43.

19. Young MS. Preparing dermatology nurses: biologic therapy for psoriasis. Dermatol Nurs 2003; 15(5): 413-24.

20. Leone G, Rolston K, Spaulding G. Alefacept for chronic plaque psoriasis: a selective therapy with long-lasting disease remissions and an encouraging safety profile. Dermatol Nurs 2003; I5(3): $216-26$.

21. Mikula C. Balneo-phototherapy: a new holistic approach to treating psoriasis. J Am Acad Nurse Pract 2003; 1 5(6): 253-9.

22. Weiss SC, Bergstrom KG, Weiss SA, Kimball AB. Quality of life considerations in psoriasis treatment. Dermatol Nurs 2003; 15(2): 120-8.

23. Watson T, Bruin G. Impact of Cutaneous Disease on the SelfConcept: An Existential-Phenomenological Study of Men and Women with Psoriasis. Dermatol Nurs 2007; 19(4): 35 I-64.

24. Jankowiak B, Lukaszuk, C, Krajewska-Kulak E, Niczyporuk, W, Van Damme-Ostapowicz K, Baranowska A, et al. The need for health education among patients with psoriasis. Dermatol Nurs 2004; 16(5): 439-44

25. National Psoriasis Foundation. Press kit for psoriatic arthritis survey. April 2002. [cited 2009 Apr 10]. Available from: http:/ /www.psoriasis.org/images/papresskit.pdf

26. Martini JG. Mas, do Que é mesmo Que estamos falando Quando abordamos a integralidade? Rev Bras Enferm 2008; 6 I (3): 285.

27. Petros HM. What's your assessment? Palmoplantar pustulosis. Dermatol Nurs 2008;20(3):203-5.

28. Winkelman WJ, Halifax NV. Power is only skin deep: an institutional ethnography of nurse-driven outpatient psoriasis treatment in the era of clinic web sites. J Med Syst 2007; 3 I (2): I3 I-9.

29. Guldbakke KK, Khachemoune A. Guttate psoriasis. Dermatol Nurs 2006; 18(4): 369.

30. Grillo M, Long R, Long D. Habit reversal training for the itchscratch cycle associated with pruritic skin conditions. Dermatol Nurs 2007; 19(3): 243-9.

31. Cunha ICKO. Vencido o desafio: a biblioteca virtual em saúde enfermagem está no ar. Rev Bras Enferm 2006; 59(5): 599.

32. Martini JG. O papel social da pesquisa em enfermagem. Rev Bras Enferm 2009; 62(3): 340. 